\title{
Development of Synthetic Soil Mixture for Experimental Shaking Table Tests on Building Frames Resting on Soft Soils
}

\author{
Hamid Reza Tabatabaiefar \\ School of Engineering and Information Technology, Faculty of Science and Technology, Federation University Australia, \\ Australia
}

\begin{abstract}
In this study, a synthetic soil mixture has been developed and proposed for experimental soilstructure interaction shaking table tests on building frames with shallow foundations resting on soft soil deposits. The proposed mix provides adequate undrained shear strength to mobilise the required shallow foundation bearing capacity underneath the structural model while meeting both criteria of dynamic similarity between the model and the prototype to model soft soils in shaking table tests. To find the most appropriate mixture, different mixes with different proportion of mix components were examined in the soils laboratory. Performing bender element tests, shear wave velocity of the soil specimens was acquired at different cure ages and the results were examined and compared. Based on the test results, a synthetic clay mixture consisting of kaolinite clay, bentonite, fly ash, lime and water has been proposed for experimental shaking table tests.
\end{abstract}

Keywords: Synthetic Soil Mixture, Soil-Structure Interaction, Shaking Table Test, Shallow Foundations, Soft Soils.

\section{Introduction}

The problem of Soil-Structure Interaction (SSI) in seismic analysis and design of structures has become increasingly important, as it may be inevitable to build structures at locations with less favourable geotechnical conditions in seismically active regions. In addition, the scarcity of land compels engineers to construct major structures over soft deposits (Massumi \& Tabatabaiefar, 2007; Fatahi et al., 2011). During the recent years, the importance of dynamic soil-structure interaction for building structures with shallow foundations founded on soft soils has been well recognised and studied (Samali et al., 2011; Tabatabaiefar et al, 2014a). Dynamic soil-structure interaction has significant effects on seismic response of building frames resting on soft soil deposits. Considering performance-base design approach, the amplification of lateral deformations due to SSI

\footnotetext{
* Correspondence to: Hamid Reza Tabatabaiefar, Lecturer, Federation University Australia, Office Y231, Building Y, Mt Helen Campus, PO Box 663 Ballarat VIC 3353, Australia, Tel.: +61 35327 6718, E-mail address: h.tabatabaiefar@federation.edu.au.
} 
noticeably changes the performance level of the building frames (Tabatabaiefar et al., 2013a,b). Consequently, the safety and integrity of the building would be endangered. Thus, the conventional design procedure excluding SSI may not be adequate to guarantee the structural safety of building frames resting on soft soil deposits (Tabatabaiefar et al., 2012; Fatahi \& Tabatabaiefar, 2014b). As a result, there is a strong

need to develop numerical and experimental tools to evaluate the seismic response of building structures resting on soft soil deposits under the influence of soil-structure interaction. In response to this need, in this study, a synthetic soil mixture has been developed and proposed for experimental SSI shaking table tests on building frames resting on soft soils.

\section{Background}

According to Meymand (1998), Moss et al. (2010) and Turan et al. (2013) reconstituted soils are unable to satisfy the scale modelling criterion of shear wave velocity with enough bearing capacity for the foundation in SSI shaking table tests on buildings with shallow foundations resting on soft soils. They proposed synthetic clay mixtures which provide adequate undrained shear strength to mobilise the required shallow foundation bearing capacity underneath the structural model while meeting the scale modelling criterion of shear wave velocity. If the underneath soil does not provide enough bearing capacity for the structural model foundation, the underneath soil may experience failure or excessive settlements while shaking table testing process is being undertaken. In addition, Turan et al. (2009) and Moss et al. (2010) pointed out that employing a reconstituted soil is deemed impractical in shaking table tests due to the large size of the 
test container and the very long time that would be required for consolidation in a 1-g environment. Thus, in this study, a synthetic clay mixture, which meets the scale modelling criteria of shear wave velocity and adequate bearing capacity for the foundation, has been developed to be employed as the soil medium for SSI shaking table testing programmes.

\section{Scaling Factors for Shaking Table Testing}

Meymand (1998) has denoted that "scale models can be defined as having geometric, kinematic, or dynamic similarities to the prototype. Geometric similarity defines a model and prototype with homologous physical dimensions. Kinematic similarity refers to a model and prototype with homologous particles at homologous points at homologous times. Dynamic similarity describes a condition where homologous parts of the model and prototype experience homologous net forces.” Meymand (1998) also explained that "scale models meet the requirements of similitude to the prototype to differing degrees, and researchers may apply nomenclature such as "true”, "adequate”, or "distorted" to the model. A true model fulfils all similitude requirements. An adequate model correctly scales the primary features of the problem, with secondary influences allowed to deviate while the prediction equation is not significantly affected. Distorted models refer to those cases in which deviation from similitude requirements distorts the prediction equation, or where compensating distortions in other dimensionless products are introduced to preserve the prediction equation. 1-g scale modelling, where, $\rho$ is density, $E$ is modulus of elasticity, $a$ is acceleration, and $g$ is gravitational acceleration, the dimensionless product $a / g$ (Froude’s number) must be kept 
equal to unity implying that the ratio of model to prototype specific stiffness $(E / \rho)$ is equal to the geometric scaling factor $\lambda$.” This is known as Cauchy condition which can also be stated in terms of shear wave velocity as follows:

$\frac{\left(V_{S}\right)_{p}}{\left(V_{S}\right)_{m}}=\lambda^{1 / 2}$

where, subscripts $p$ and $m$ stand for prototype, and model, respectively, and $V_{s}$ is shear wave velocity.

In addition, Moncarz and Krawinkler (1981) showed that satisfying the Cauchy condition is an essential requirement for simultaneous replication of restoring forces, inertial forces, and gravitational forces in a dynamic system. Iai (1989) derived a comprehensive set of scaling relations for a soil-structure system under dynamic loading and defined the entire problem in terms of geometric, density, and strain scaling factors. This method relates the geometric $(\lambda)$ and density $\left(\lambda_{p}\right)$ scaling factors, and then derives the strain scaling factor ( $\lambda_{\varepsilon}$ ) from shear wave velocity tests on both the model and prototype soil, as presented in Equation (2).

$\lambda_{\varepsilon}=\left[\frac{\lambda}{\left(\frac{\left(V_{S}\right)_{p}}{\left(V_{S}\right)_{m}}\right)^{2}}\right]$

Meymand (1998) explained that "no governing equation can be written describing the entire soil-structure system, nor can dimensional analysis or similitude theory be directly applied to this complex system to achieve "true" model similarity. The viable scale modelling approach for application of scale model similitude therefore consists of 
identifying and successfully modelling the primary forces and processes in the system, while suppressing secondary effects, thereby yielding an "adequate” model.”

Several researchers (e.g. Meymand, 1998; Moss et al., 2010; Turan et al., 2013) pointed out that in order to achieve an adequate model for dynamic soil-structure interaction simulation in shaking table tests, Cauchy condition (Equation 1), should be satisfied. In addition, the strain scaling factor $\left(\lambda_{\varepsilon}\right)$ should be kept equal to one. It should be noted that when Cauchy condition is satisfied, obviously, the result of substituting the value of $\left(V_{s}\right)_{p}$ $/\left(V_{s}\right)_{m}$ from Equation (1) into Equation (2) is equal to one.

The objective of the scale modelling procedure for this test program is to achieve "dynamic similarity", where model and prototype experience homologous forces. For this purpose, adopted methodology by Meymand (1998) is the framework for scale model similitude in this study.

In Table 1 , the shear wave velocity scaling factor $\left(\left(V_{s}\right)_{p} /\left(V_{s}\right)_{m}\right)$ is equal to $\lambda^{1 / 2}$. Therefore, Cauchy condition (Equation 1) is met in the scaling relations. In addition, strain scaling factor $\left(\lambda_{\varepsilon}\right)$, which can be determined by substituting the value of $\left(V_{s}\right)_{p} /\left(V_{s}\right)_{m}$ from Equation (1) into Equation (2), is kept equal to one. Thus, as mentioned earlier, both requirements for achieving an adequate model for dynamic soil-structure interaction simulation in shaking table tests are satisfied.

\section{Characteristics of Soil Model}

In this study, in order to model a soft soil deposit, the shear wave velocity of the prototype soil $\left(V_{s}\right)_{p}$ is considered to be $200 \mathrm{~m} / \mathrm{s}$ while prototype soil density is $1470 \mathrm{~kg} / \mathrm{m}^{3}$. 
Horpibulsuk et al. (2010), Moss et al. (2010) and Sulaeman (2010) elucidated that the parameters describing dynamic soil properties in soil-structure interaction phenomenon are shear wave velocity, density, modulus degradation, damping, and stress-strain response. These parameters are discrete and nonlinear, and are functions of the loading rate, the number of cycles, and strain reversals. When the unit weight of the soil model is considered to be equal to the unit weight of the prototype soil, as explained in Section 3, then one scaling condition can be determined. Meymand (1998) explained that "the nonlinear stress-strain and modulus degradation and damping curves are not directly modelled from a prototype case, but rather the method of implied prototypes is used to consider whether the scale model properties for these parameters are reasonable. This leaves undrained shear strength and shear modulus (or shear wave velocity) as the principal soil modelling criteria”. However, only shear modulus (or shear wave velocity) has been considered as the principal soil modelling criterion by several other studies (e.g. Sulaeman, 2010; Lee et al., 2012; Turan et al., 2013). Therefore, in this study, the principle soil modelling criterion is deemed to be shear wave velocity. Considering the specifications of employed shaking table, scaling factor of 1:30 provides the largest achievable scale model with rational scales, maximum payload, and overturning moment which meet the facility limitations (Tabatabaiefar et al., 2014c). Thus, geometric scaling factor $(\lambda)$ of 1:30 is adopted for experimental shaking table tests on the scale model in this study.

According to Table 1, scaling factor between shear wave velocity of the soil model $\left(V_{s}\right)_{m}$ and shear wave velocity of the prototype soil $\left(V_{s}\right)_{p}$ can be expressed as follows: 


$$
\frac{\left(V_{s}\right)_{m}}{\left(V_{s}\right)_{p}}=\lambda^{1 / 2}=0.182
$$

Knowing the shear wave velocity of the prototype soil $\left(V_{s}\right)_{p}$, the shear wave velocity of the soil model $\left(V_{s}\right)_{m}$ can be determined from Equation (3) as follows:

$$
\left(V_{s}\right)_{m}=0.182 \times\left(V_{s}\right)_{p}=0.182 \times 200=36.4 \mathrm{~m} / \mathrm{s}
$$

Therefore, in order to achieve dynamic similarity, the soil model should have the shear wave velocity $\left(V_{s}\right)_{m}$ and soil density of $36.4 \mathrm{~m} / \mathrm{s}$ and $1470 \mathrm{~kg} / \mathrm{m}^{3}$, respectively.

\section{Development of Soil Mix}

Meymand (1998), Turan et al. (2009), and Moss et al. (2010) adopted synthetic clay mixture reporting that a reconstituted soil would not be able to satisfy the competing scale modelling criterion of shear wave velocity with enough bearing capacity for the foundation in shaking table tests while synthetic clay mix provides adequate undrained shear strength to mobilise the required shallow foundation bearing capacity underneath the structural model meeting the scale modelling criterion of shear wave velocity. If the underneath soil does not provide enough bearing capacity for the structural model foundation, the underneath soil may experience failure or excessive settlements while testing process is being undertaken. In addition, Meymand (1998) and Moss et al. (2010) pointed out that employing a reconstituted soil is deemed impractical in shaking table tests due to the large size of the test container and the very long time that would be required for consolidation in a 1-g environment. Thus, in this study, a synthetic clay mixture, which meets the contending scale modelling criterion of shear wave velocity with adequate bearing capacity for the foundation, was adopted as the soil medium for the shaking table testing process. In order to develop the synthetic clay mixture, in this study, 
Q38 kaolinite clay, ActiveBond 23 bentonite, Class F fly ash, lime and water have been used as the main mix materials. Q38 kaolinite clay is a dry milled kaolin China clay of a white-cream colour. Kaolinite is formed by the breakdown of feldspar, which is induced by water and carbon dioxide and is often formed by the alteration of aluminium silicate minerals in a warm and humid environment (Craig, 2000; Murray, 1999). The kaolinite samples had an average liquid limit and plastic limit of 50\% and 30\%, respectively. ActiveBond 23 bentonite is a pure form of bentonite, which is plastic, impermeable, having a high absorbing and swelling capacity and is high viscous when suspended in water (Churchman, 2000). The bentonite samples acquired average liquid limit and plastic limit of 340\% and 55\%, respectively. The burning of hard, old anthracite and bituminous coal typically produces Class F fly ash. This fly ash is pozzolanic in nature, and contains less than $20 \%$ lime (CaO). Possessing pozzolanic properties, the glassy silica and alumina of Class F fly ash requires a cementing agent, such as Portland cement, quicklime, or hydrated lime, with the presence of water in order to react and produce cementitious compounds (Siddique, 2002). Combination of (4 class F fly ash): (1 quick lime) was utilised in the mix. According to Wartman (1996), this combination acts as a chemically reactive material when mixed with the kaolinite-bentonite clay. The chemical reactivity is attributed to the high calcium oxide content of the fly ash. When mixed with the clay, the combination causes rapid cation exchange to occur on the clay minerals leading to a substantial reduction in plasticity. The cation exchange causes the double layer around the clay mineral to shrink resulting in an increase in stiffness and by association, shear wave velocity. Figure 1, shows the different dry components of the soil mix in three different containers. 
To find the most appropriate mix for the test program, three different mixes, including Mix A, Mix B, and Mix C were developed and examined in soils laboratory. The proportion of different mix components for the three mixes are summarised in Table 2.

Mix A, which is the closest mix to the proposed mix by Meymand (1998), has higher percentages of kaolinite and bentinite, lower percentage of class F fly ash and lime, and the same percentage of water content comparing to Mix B. Mix B and C have the same dry component percentages, but the water content which is expected to provide the key elements of mixability and workability for shake table model testing was increased by $20 \%$ in Mix C in comparison to Mix B in order to achieve better mixibility and workability for the mix. Each proposed mix was prepared three times to control repeatability of the test and each time three cylindrical test specimens of size $D=50 \mathrm{~mm}$ and $h=100 \mathrm{~mm}$ were taken (Figure 2a).

During the mixing procedure, first dry kaolinite and bentonite were added to the mixing container and mixed in dry condition using spatula. Then, fly ash and lime, which had been combined separately, added to the dry mix and completely mixed using spatula in order to form a homogenous dry mix. Afterwards, water was added in a slow and successive manner while the whole components were being mixed inside the mixing container. Alternating hand and mechanical mixing was introduced to ensure a homogenous mix for all samples. The resulting mixtures were of reasonable workability for placement into the moulds; particularly, Mix C had the highest workability among the other mixtures. In an effort to minimise entrapped air and to provide compaction, the mixture was placed into the mould in several layers and worked into the mould with palette knives (Figure 2b). It should be noted that in order to seal the specimens, plastic sheets were wrapped around the final specimens to 
minimise moisture loss and assist the cation exchange process. Afterwards, all specimens were stored in an identical controlled ambient environment of $25^{\circ} \mathrm{C}$ and after one day of cure age, the specimens were de-moulded to be prepared for shear wave velocity measurement at different cure ages by performing bender element tests. The elapsed time from specimen preparation to testing is termed "cure age". The bender element test is a non-destructive test that has gained popularity in the laboratory determination of small strain shear modulus. Bender elements are essentially a pair of piezoelectric transducers (top cap at the top and support pedestal at the bottom) and two porous plates (Figure 3).

When a bender element is deformed, the lattice distorts the dipole moment of the crystal and a voltage is generated. Conversely applying a voltage potential causes a bender element to deform. Hence bender elements can be used as either shear wave or compressional wave sources or receivers. Bender elements couple well with the soil, and mechanically similar bender elements operate in the same frequency range and are therefore "tuned" to each other. The bender element systems connect directly into a master control box (Figure 4) which, in turn connects to a PC running bender elements control software.

To perform bender element tests, the soil specimens were placed between bender elements (Figure 4), and shear wave velocity of each soil specimen was obtained at different cure ages by measuring the time required for the wave to travel between two bender elements using PC running bender element control software. It should be noted that the propagated shear wave type was sine wave with amplitude of 10 volts (V) and period of 1 second. 
The above mentioned test procedure has been repeated for nine soil specimens taken from mixes A, B, and C, respectively, over 14 successive days. Figure 5 illustrates the extracted average shear wave velocities versus cure ages for the three different mixes over the period of two weeks.

Observing the obtained shear wave velocity values in Figure 5, it is evident that the shear wave velocity values of all three mixes increase by increase of the cure age as expected (e.g. Wartman, 1996; Riemer, et al., 1998; Meymand, 1998; Moss et al., 2010). This means the examined soil mixes gain stiffness and consequently shear wave velocity increase over the cure age. As a result, if the curing age exceeds two days, the soil mix attributes will not be conforming to a soft soil deposit prototype with shear wave velocity of $200 \mathrm{~m} / \mathrm{s}$. Therefore, maximum lateral deflection amplifications due to soil-structure interaction for building structures on soft soil deposits cannot be fully studied and captured. In addition, it is noted that only Mix C produces the required shear wave velocity $\left(V_{s}\right)_{m}$ of $36 \mathrm{~m} / \mathrm{s}$ for the soil model on the second day of its cure age while the other two mixes are unable to produce such a low shear wave velocity as required. Therefore, Mix $\mathrm{C}$ has been selected as the appropriate mix for shaking table tests in this study. However, further checks regarding the bearing capacity and density of the material is required which will be explained in Section 6. Horpibulsuk et al. (2010) after performing comprehensive laboratory tests elucidated that behaviour of cemented soils (similar to the soil mix proposed in this study) can be very similar to over consolidated soils. Thus, shear modulus degradation and damping of the adopted soil mix are deemed be similar to over consolidated soils. 


\section{Properties of the Selected Soil Mix}

As mentioned in Section 5, the shear wave velocity of Mix C on the second day of the cure age matches the targeted value of the soil shear wave velocity. If the soil density during the same cure age is equal to prototype soil density, both criteria to achieve dynamic similarity between the model and the prototype soil are met. Therefore, Mix C has been reproduced in the soils laboratory and the standard method of soil particle density determination was performed on the second day of the cure age according to AS 1289.3.5.1-2006 (Methods of testing soils for engineering purposes). Accordingly, soil density $\left(\rho_{s}\right)$ in the second day of the cure age was determined to be $1450 \mathrm{~kg} / \mathrm{m}^{3}$ which is almost equal to the prototype soil density $\left(1470 \mathrm{~kg} / \mathrm{m}^{3}\right)$. Thus, shear wave velocity and soil density values of Mix $\mathrm{C}$ on the second curing day satisfies the dynamic similarity requirements. It should be noted that effects of composition on the soil mix density has not been considered in the testing program. In addition, as mentioned earlier, the soil model undrained shear strength is supposed to be adequate to satisfy the required shallow foundation bearing capacity underneath the structural model. In order to check the undrained shear capacity, three cylindrical test specimens of size $D=100 \mathrm{~mm}$ and $h=200 \mathrm{~mm}$ were taken and sealed (Figure 6a) from Mix C with the mixing and moulding process described in Section 5. Then, on the second day of the samples cure age, Unconfined Compression tests (UC) were performed on the three soil specimens in accordance with AS5101.4-2008 (Method 4: unconfined compressive strength of compacted materials) in order to determine soil shear strength. Figure 6b depicts a failed specimen after undertaking the test. The average undrained shear strength $\left(C_{u}\right)$ of Mix $\mathrm{C}$ on the second day of the cure age, resulting from three examined specimens, was $1.57 \mathrm{kPa}$. According 
to the laboratory measurements, the total measured mass of the structural model considering the mass of the base plate is $115 \mathrm{~kg}$. Based on the carried out foundation calculations, by adopting $1.57 \mathrm{kPa}$ as the undrained shear strength, the soil mix will provide enough bearing capacity with acceptable factor of safety under the structural model on the second day of the cure age to avoid any failure or excessive settlement underneath the structure $\left(q_{u l t}=5.14 \mathrm{C}_{\mathrm{u}}, \mathrm{FoS}>2.0\right)$. Details of the structural model have been elucidated by Tabatabaiefar et al. (2014c). Eventually, the selected soil mix (Mix C) on the second day of the cure age is expected to have the properties summarised in Table 3. It should be noted that the soil mix bearing capacity is adequate for the utilised 15 storey structural model with the mass of $115 \mathrm{~kg}$. For heavier or taller structural models (e.g. 30 storey structural model), a thorough foundation bearing capacity check procedure is required to be undertaken to ensure no failure or excessive settlement underneath the structure can be taken place.

As the soil mix (Mix C) consists of cementitious materials (e.g. lime with fly ash), the cementation degradation of the subsoil due to the applied loads may become an issue under the seismic loads during shaking table tests. Nguyen et al. (2014) indicated that "laboratory experiments show that the effect of cementation on clays gradually diminishes as the confining pressure increases (particularly at high confining pressures) due to the degradation of cementation bonds". They also elucidated that the effects of cementation on the pre and post failure behaviour of cemented clays can be observed at microstructural level through X-ray diffraction (XRD) and scanning electron microscopy (SEM). While the untreated clay exhibits an open type of microstructure, with thin and flat clay particles spreading over a large area, the cemented clay shows evidence of flocculated structure with large treated particle clusters 
interspersed by large openings. At the same time, while the flocculated structure becomes more evident as the cement content increases, the platiness of the structure becomes less evident. In addition, it should be noted that the hydration process of the soil mix involves hardening and strengthening. The soil mix during this process may become unsaturated; influencing the deformation of the soil and excessing pore water and air pressures under the applied loads (Ho et al., 2014) during shaking table tests.

\section{Conclusions}

Reconstituted soils are not appropriate options for SSI shaking table tests on buildings with shallow foundations resting on soft soil deposits. They are unable to satisfy the required scale modelling criterion of shear wave velocity with enough bearing capacity for the foundation on soft soil models. Using reconstituted soils can be led to failure or excessive settlements underneath the building model shallow foundation while shaking table testing process is undertaken. In addition, employing reconstituted soils in the mentioned tests is deemed to be unreasonable due to large size of the test container and the very long time that would be required for consolidation in a 1-g environment. Thus, in order to overcome the mentioned weaknesses of reconstituted soils in SSI shaking table tests, in this study, a synthetic soil mixture has been developed for experimental SSI shaking table tests on building frames resting on soft soils. It should be noted that the proposed mix has been designed to develop a soil mix with shear wave velocity of $36 \mathrm{~m} / \mathrm{s}$ on the second day of

cure age corresponding to a prototype soil with shear wave velocity of $200 \mathrm{~m} / \mathrm{s}$ and is applicable to this case only. 
To find the most appropriate mix, three different mixes with different proportions of mix components were developed and examined in soils laboratory. Performing bender element tests, shear wave velocities of the soil specimens were obtained at different cure ages from three mixes over 14 successive days. Based on the test results, a synthetic clay mixture consisting of 60\% kaolinite clay, 20\% bentonite, 20\% Class F fly ash and lime and 120\% water has been developed and proposed for SSI shaking table tests of buildings on soft soils. The proposed mix provides adequate undrained shear strength to mobilise the required shallow foundation bearing capacity underneath the structural model while meeting the scale modelling criterion of shear wave velocity to model soft soil deposits in the laboratory. In addition, soil density of the proposed mix during the same cure age is equal to prototype soil density. Therefore, the developed soil mix meets both criteria of dynamic similarity between the model and the prototype. Additionally, workability and mixibility of the mix is very high which eases the production and placement of the clay mixture into the shaking table soil container. 


\section{References}

AS1289.3.5.1-2006, Methods of testing soils for engineering purposes, Determination of the soil particle density of a soil-standard method, Australian Standards, Sydney.

AS5101.4-2008, Methods for preparation and testing of stabilised materials, Method 4: unconfined compressive strength of compacted materials, Australian Standards, Sydney.

Craig, H. 2000, Soil Mechanics, Chapman and Hall, London.

Fatahi, B \& Tabatabaiefar, H.R. 2014, 'Fully Nonlinear Versus Equivalent Linear Computation Method For Seismic Analysis of Mid-Rise Buildings on Soft Soils', International Journal of Geomechanics, vol. 14, no. 4, , ASCE Press.

Fatahi, B., Tabatabaiefar, H.R. \& Samali, B. 2011, 'Performance Based Assessment of Dynamic Soil-Structure Interaction Effects on Seismic Response of Building Frame', Proceedings of Georisk 2011 - Geotechnical Risk Assessment \& Management (Geotechnical Special Publication No. 224), American Society of Civil Engineers (ASCE), pp. 344-351.

Ho. L., Fatahi, B. and Khabbaz, H. 2014, 'Analytical Solution of One-dimensional Consolidation of Unsaturated Soils Using Eigenfunction Expansion Method', International Journal for Numerical and Analytical Methods in Geomechanics, vol. 38, no. 10, pp. 1058-1077.

Horpibulsuk, S., Lie, M.D., Liyanapathirana, D.S. \& Suebsuk, J. 2010, 'Behaviour of cemented clay simulated via the theoretical framework of the structured Cam Clay model', Computers and Geomechanics, vol. 37, no.1-2, pp.1-9.

Iai, S. 1989, 'Similitude for Shaking Table Tests on Soil-Structure-Fluid Model in 1g Gravitational Field', Soils and Foundations, vol. 29, no. 1, pp. 105-118.

Langhaar, H. 1951, Dimensional Analysis and Theory of Models, John Wiley \& Sons Inc., New York.

Lee, CH., Wei, Y. \& Huo, Y. 2012, 'Boundary Effects of a Laminar Container in Centrifuge Shaking Table Tests', Soil Dynamics and Earthquake Engineering, vol. 34, no. 1, pp. 37-51.

Massumi, A. \& Tabatabaiefar, H.R. 2007, 'Effects of Soil-Structure Interaction on Seismic Behaviour of Ductile Reinforced Concrete Moment Resisting Frames', Proceedings of World Housing Congress on Affordable Quality Housing (WHC2007), Putra, Malaysia.

Meymand, P.J. 1998, 'Shaking Table Scale Model Tests of Nonlinear Soil-Pile-Superstructure Interaction in Soft Clay', PhD thesis in Civil Engineering, University of California, Berkeley.

Moncarz, P. \& Krawinkler, H. 1981, Theory and Application of Experimental Model Analysis in Earthquake Engineering, Report No. 50, John Blume Earthquake Engineering Ctr., Stanford Univ.

Moss, R.E.S., Crosariol, V. \& Kuo, S. 2010, 'Shake Table Testing to Quantify Seismic SoilStructure Interaction of Underground Structures', Proceedings of the 5th International Conference on Recent Advances in Geotechnical Earthquake Engineering and Soil Dynamics, May 24-29, San Diego, Paper No. 1.27b.

Murray, H.H. 1999, 'Applied Clay Mineralogy Today and Tomorrow', Clay Minerals, vol. 34, no. 1, pp. 39-49. 
Nguyen, L.M., Fatahi, B. and Khabbaz, H. 2014, 'A Constitutive Model for Cemented Clays Capturing Cementation Degradation', International Journal of Plasticity, vol. 56, pp.1-18.

Riemer, M., Gookin, W., Bray, J. \& Wartman, J. 1998, 'Using Reflected Waves to Measure Small Strain Dynamic Properties', Proceedings of the 5th Caltrans Seismic Research Workshop, Sacramento, pp. 16-18.

Samali, B., Fatahi, B. \& Tabatabaiefar, H.R. 2011, 'Seismic behaviour of Concrete Moment Resisting Buildings on Soft Soil Considering Soil-Structure Interaction', Proceedings of the 21st Australasian Conference on the Mechanics of Structures and Materials (ACMSM21), pp. 407-412.

Siddique, R. 2002, 'Effect of Fine Aggregate Replacement with Class F Fly Ash on the Mechanical Properties of Concrete', Cement and Concrete Research, vol. 33, no. 4, pp. 539-547.

Sulaeman, A. 2010, 'The Use of Lightweight Concrete Piles for Deep Foundation on Soft Soils', $\mathrm{PhD}$ thesis in Civil Engineering, University of Tun Hussein Onn, Malaysia.

Tabatabaiefar, H.R., Fatahi, B. \& Samali, B. 2012, 'Finite Difference Modelling of Soil-Structure Interaction for Seismic Design of Moment Resisting Building Frames', Australian Geomechanis Journal, vol. 47, no. 3, pp. 113-120.

Tabatabaiefar, S., Fatahi, B. \& Samali, B. 2013a, 'Seismic Behavior of Building Frames Considering Dynamic Soil-Structure Interaction', International Journal of Geomechanics, vol. 13, no. 4, pp. 409-420.

Tabatabaiefar, H.R., Fatahi, B. \& Samali, B. 2013b, 'Response of Mid-Rise Building Frames under Influence of Dynamic Soil-Structure Interaction', Structural Engineering and Mechanics, vol. 45, no. 3, pp. 311-321, Techno Press.

Tabatabaiefar, H.R., Fatahi, B. \& Samali, B. 2014a, 'An Empirical Relationship to Determine Lateral Seismic Response of Mid-Rise Building Frames under Influence of Soil-Structure Interaction', The Structural Design of Tall and Special Buildings, vol. 23, no. 7, pp. 526 548.

Tabatabaiefar, H.R. and Fatahi, B. \& Samali, B. 2014b, 'Idealisation of Soil-Structure System to Determine Inelastic Seismic Response of Mid-Rise Building Frames', Soil Dynamics and Earthquake Engineering, vol. 66, no. 11, pp. 339-351, Elsevier Ltd.

Tabatabaiefar, H.R., Fatahi, B., \& Samali, B. 2014c, 'Numerical and Experimental Investigations on Seismic Response of Building Frames under Influence of Soil-Structure Interaction', Advances in Structural Engineering, vol. 17, no. 1, pp. 109-130, Multi-Science Publishing.

Turan, A., Hinchberger,S. \& El Naggar, H. 2009, 'Mechanical Characterization of an Artificial Clay', Journal of Geotecnical and Geoenvironmental Engineering, vol. 135, no. 2, pp. 280290.

Turan, A., Hinchberger,S. \& El Naggar, H. 2013, 'Seismic Soil-Structure Interaction in Buildings on Stiff Clay with Embedded Basement Stories', Canadian Geotechnical Journal, vol. 50, no. 8, pp. 858-873.

Wartman, J. 1996, 'A Laboratory Study of the Effects of Fly Ash on the Geotechnical Properties of Soft Clay', MEng thesis, University of California, Berkeley. 


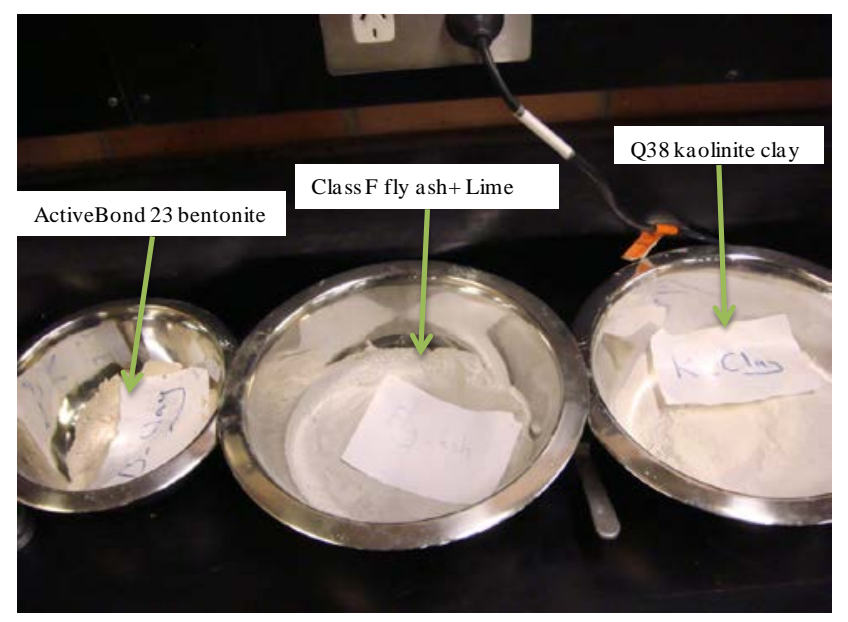

Figure 1: Different dry components of the soil mix 


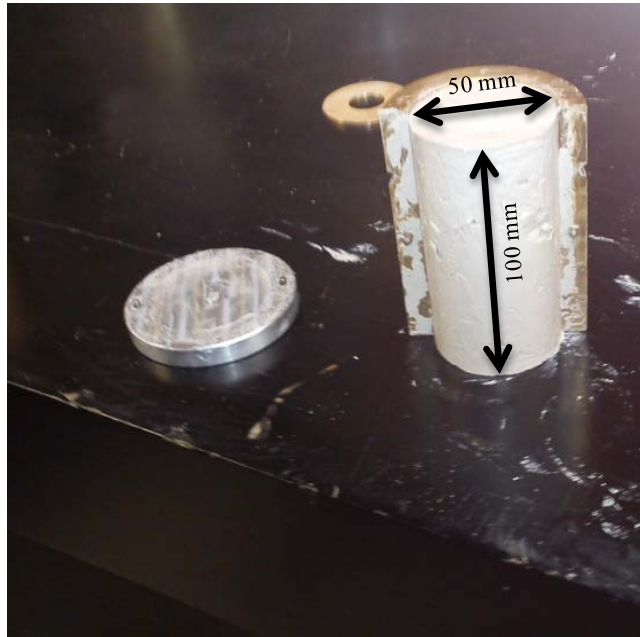

(a)

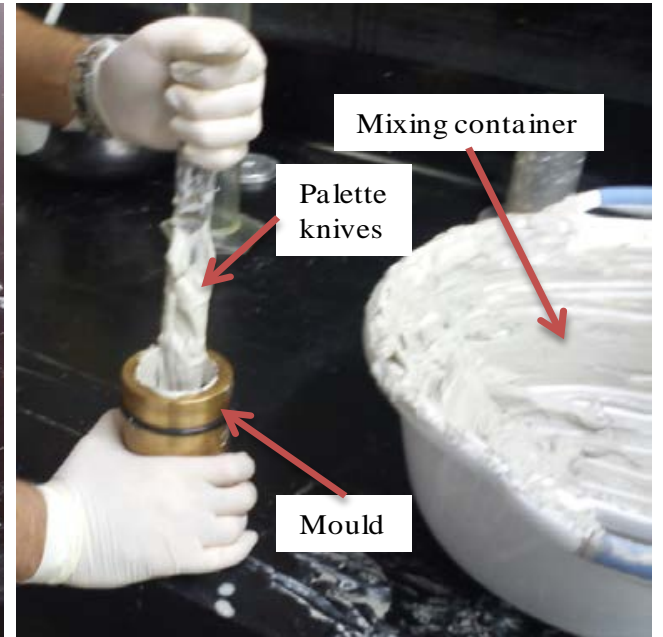

(b)

Figure 2: (a) Soil mix cylindrical test specimen; (b) placing the mixtures into the mould with palette knives 


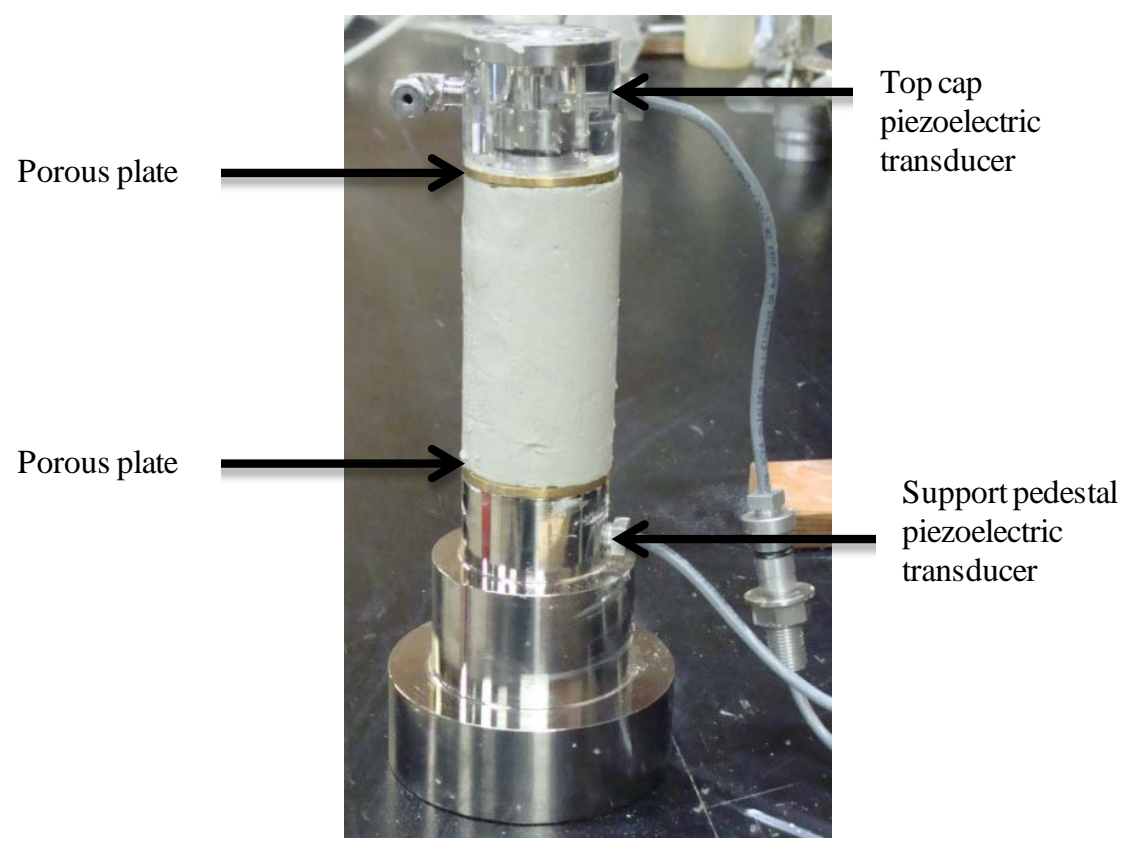

Figure 3: Bender element piezoelectric transducers 


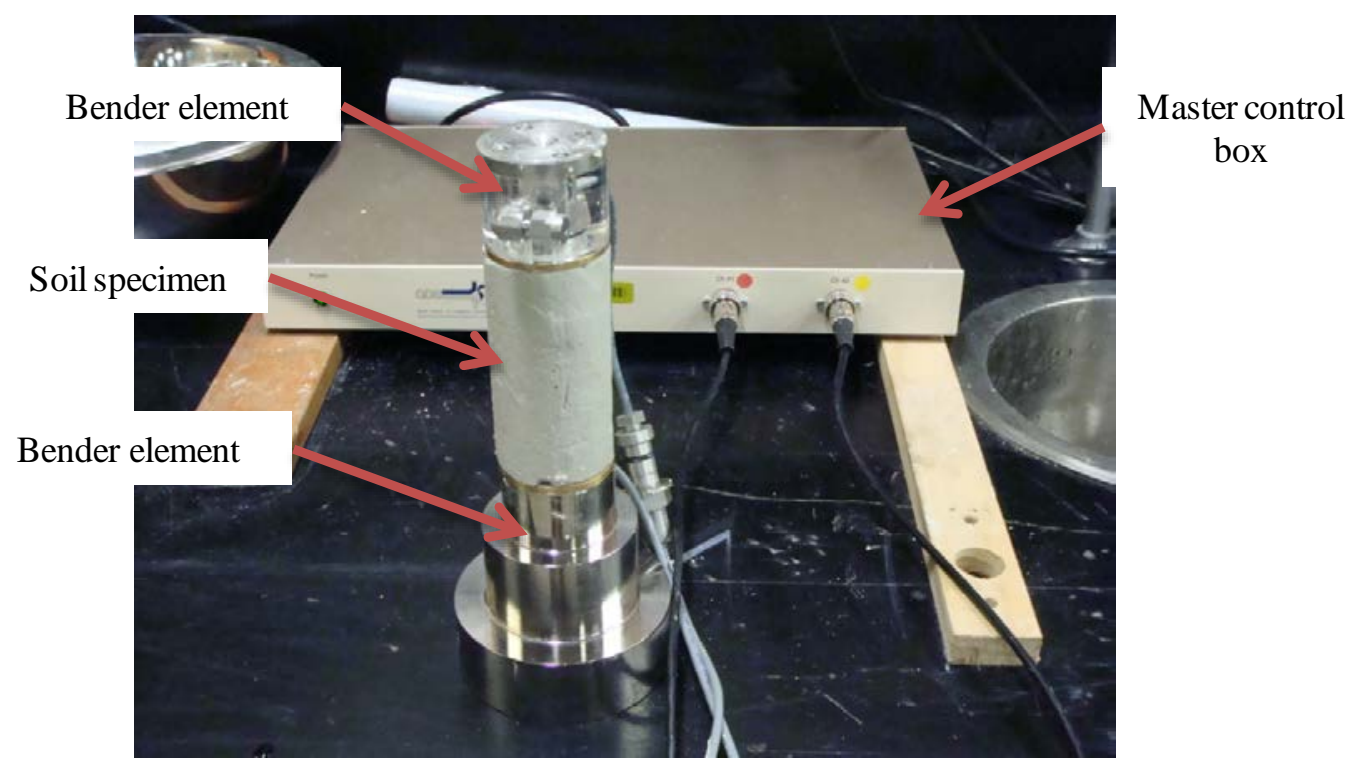

Figure 4: Soil specimen placed between bender elements 


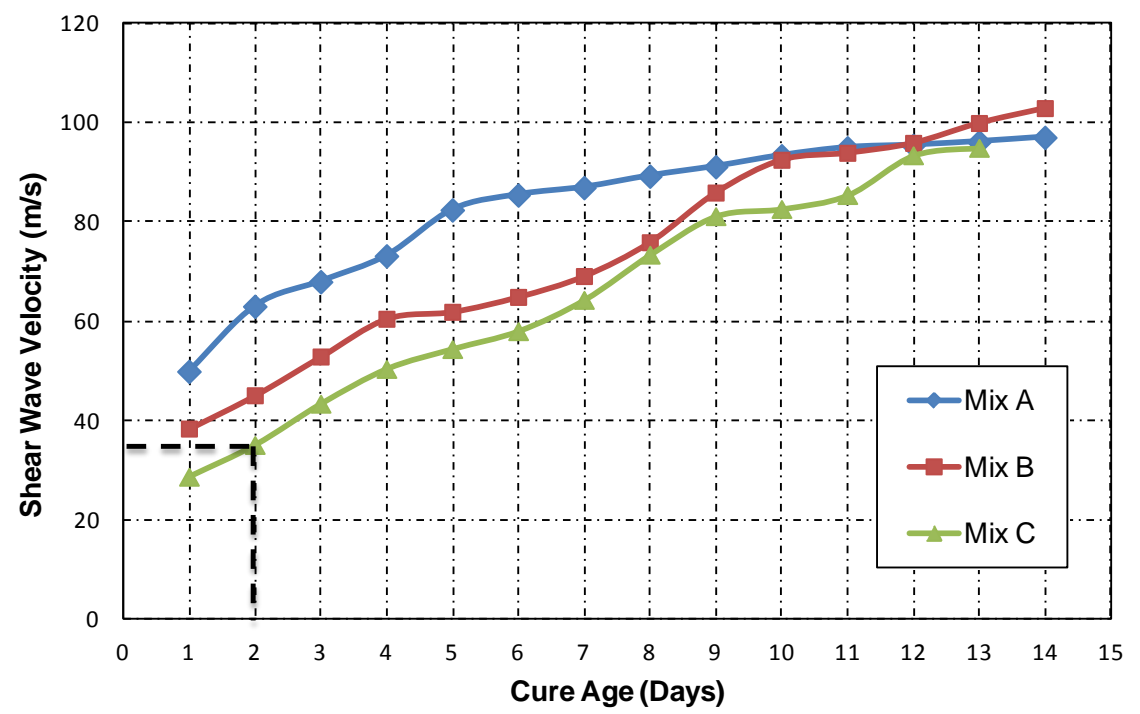

Figure 5: Shear wave velocities versus cure age for the examined mixes 


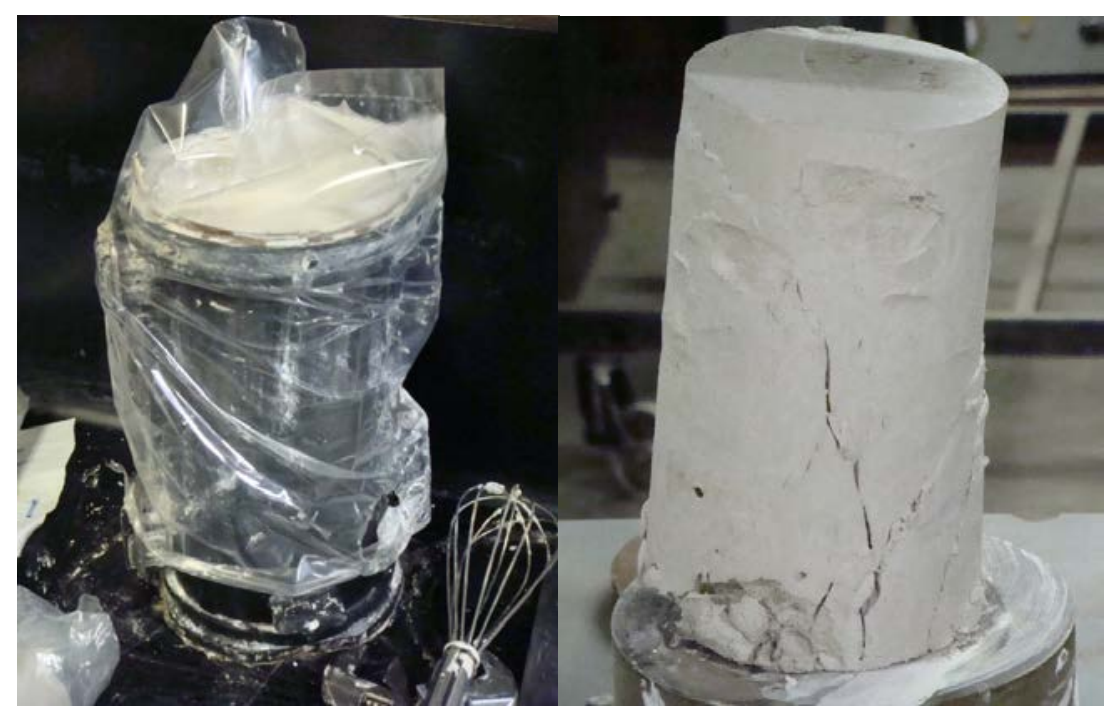

(a)

(b)

Figure 6: (a) Sealed soil Mix C cylindrical test specimen of size $D=100 \mathrm{~mm}$ and $\mathrm{h}=200 \mathrm{~mm}$; (b) failed soil specimen after performing Unconfined Compression test 
Table 1: Scaling relations in terms of geometric scaling factor $(\lambda)$

\begin{tabular}{|l|c|l|c|l|c|}
\hline Mass Density & $\mathbf{1}$ & Acceleration & $\mathbf{1}$ & Length & $\boldsymbol{\lambda}$ \\
\hline Force & $\lambda^{3}$ & Shear Wave Velocity & $\lambda^{\mathbf{1} 2}$ & Stress & $\boldsymbol{\lambda}$ \\
\hline Stiffness & $\lambda^{2}$ & Time & $\lambda^{\mathbf{1} 2}$ & Strain & $\mathbf{1}$ \\
\hline Modulus & $\lambda$ & Frequency & $\lambda^{-1 / 2}$ & EI & $\lambda^{5}$ \\
\hline
\end{tabular}


Table 2: Proportion of different components for the examined mixtures

\begin{tabular}{cccc}
\hline Mix Components & Mix A & Mix B & Mix C \\
\hline Q38 kaolinite clay & $67.5 \%$ & $60 \%$ & $60 \%$ \\
ActiveBond 23 bentonite & $22.5 \%$ & $20 \%$ & $20 \%$ \\
Class F fly ash+ Lime & $10 \%$ & $20 \%$ & $20 \%$ \\
Water * & $100 \%$ & $100 \%$ & $120 \%$ \\
\hline
\end{tabular}

$* \%$ of the dry mix. 
Table 3: Properties of the selected soil mix on the second day of cure age

\begin{tabular}{ccc}
$\begin{array}{c}\text { Shear wave velocity } \\
\mathbf{V}_{\mathbf{s}}(\mathrm{m} / \mathrm{s})\end{array}$ & $\begin{array}{c}\text { Un-drained shear strength } \\
\mathbf{C}_{\mathbf{u}}(\mathrm{kPa})\end{array}$ & $\begin{array}{c}\text { Soil Density } \\
\boldsymbol{\rho}\left(\mathrm{kg} / \mathrm{m}^{3}\right)\end{array}$ \\
\hline 36 & 1.57 & 1450
\end{tabular}

